Portland State University

PDXScholar

$5-21-2020$

\title{
Vampires, Fandom, and Feminism: Updating the Vampire Horror Screenplay Through Themes of Empowerment
}

McKinzie Smith

Portland State University

Follow this and additional works at: https://pdxscholar.library.pdx.edu/honorstheses

Part of the Screenwriting Commons

Let us know how access to this document benefits you.

\section{Recommended Citation}

Smith, McKinzie, "Vampires, Fandom, and Feminism: Updating the Vampire Horror Screenplay Through Themes of Empowerment" (2020). University Honors Theses. Paper 868.

https://doi.org/10.15760/honors.889

This Thesis is brought to you for free and open access. It has been accepted for inclusion in University Honors Theses by an authorized administrator of PDXScholar. Please contact us if we can make this document more accessible: pdxscholar@pdx.edu. 
Vampires, Fandom, and Feminism: Updating the Vampire Horror Screenplay Through Themes of Empowerment

by

McKinzie Smith

An undergraduate honors thesis submitted in partial fulfillment of the requirements for the degree of Bachelor of Arts

in

University Honors

and

Film

Thesis Advisor

Mark Berrettini

Portland State University 


\begin{abstract}
In this thesis supplement, the three major themes of McKinzie Smith's screenplay Lifeblood are elaborated on in detail. In an effort to craft a screenplay within the horror genre that is modern and meaningful, vampire myth was adapted to apply to contemporary conversation surrounding power dynamics and gendered violence. The theme of fandom is shown to expose those power dynamics in a familiar, relatable way for a teenaged female audience. These two themes filter into the broader feminist intention of the work, aiming to provoke conversation about power in fandom spaces as well as provide catharsis for young women who may be victims of violence. Vampires, Fandom, and Feminism: Updating the Vampire Horror Screenplay Through Themes of Empowerment
\end{abstract}

Gone are the days of Twilight and Buffy the Vampire Slayer. Vampire franchises have been as dead as their protagonists for some time now, with the last vestige of the trend, The Vampire Diaries TV series, fizzling out over three years ago (Gennis). Despite this, a cultural reappraisal of this trend is currently underway, as well as a new understanding of potential feminist readings of these works (Łuksza). As a writer, it is advantageous to incorporate trends into our work, but what about nostalgia trends? With the public looking toward teen vampire stories as a vestige of days gone by, it may be time to excavate its remains. My thesis screenplay will explore this genre, but aims to add something new to the discussion. With recent films like $A$ Girl Walks Home Alone at Night (dir. Amirpour, 2014) and The Love Witch (dir. Biller, 2016) exploring women's fears and inner lives, a door has been opened for explicitly feminist monster cinema. Feminist teen monster films are often overlooked in favor of a more mature perspective, with the exceptions of Jennifer's Body (dir. Kusama, 2009); a sneakily sarcastic take on the sexually 
exploitative teen horror genre, or Carrie (dir. De Palma, 1976). As indebted as I am to these two films, they fall short of advancing feminist thought in their pursuit of a wide general audience. There is more to be said about the horrors of being a teenage girl than the current small number of films can convey. I hope to expand on this legacy by writing an updated teen monster story with roots in traditional vampire myth. To do so, I have drawn on Gothic literature, examined fangirl culture, and expanded on the monstrous-feminine trope.

\section{Summary of Thesis}

The protagonist of the story is Vanessa Sherman, a naïve sixteen year old with an obsessive personality. She has recently latched onto up-and-coming boyband Lifeblood, especially their vocalist Robbie Hart. Her two best friends, practical Sophia and easygoing Zoey, don’t understand her fascination but support her in her desire to see them in concert. Upon successfully winning a ticket to their show, Vanessa is invited by the bands team to meet Robbie post-show. They meet and he convinces her to come back to the tour bus. He seizes the moment to attack her, revealing himself as a vampire who drinks the blood of teen fangirls. Though she is rescued by Zoey and Sophia, Vanessa goes through many uncomfortable changes that night. She is able to convince her friends of her transformation into a vampire, but must hide it from her sensible parents. After a time of struggling to adapt to her new condition, Robbie breaks into Vanessa's home. She is told that she must join his coven or face death. In this world, vampires manipulate society for fame and power. Robbie uses his gaze to mind control his fans into obsessing over him, hearing music that doesn't exist, and following his every command. Vanessa refuses to join. 
In an attempt to convince her, the cult kidnaps Zoey and Sophia. Everything comes to a head at the nation's biggest music festival (a stand-in for Coachella). Vanessa follows the coven there in her parents' car. She finds her friends with the help of various members of the coven who are tired of Robbie's lifestyle. With this help, she is able to rush on stage during Lifeblood's set. In front of his fans, she exposes him as an abusive figure. She and Robbie engage in a final battle, resulting in Vanessa overpowering him, ripping out his teeth, and blinding him in an act symbolic of castration, taking away his power. Unfortunately, during the struggle Zoey is bitten by Robbie, turning her into a vampire as well. To complete the triad, Vanessa bites Sophia so they can all be immortal together. The girls return home and attempt to adapt to their new normal.

\section{The Vampire Myth: Sexuality and Fear}

The vampire myth is one rooted in fear of sexuality. To understand the vampire, one must first look at Bram Stoker's Dracula (1897). It is here that the majority of vampire movie elements come from: The sense of dangerous eroticism, the character tropes, the association with the Gothic.

As Stevenson writes in "A Vampire in the Mirror: The Sexuality of Dracula," the "real horror" of Dracula is that he is the "ultimate social adulterer" (140). Though Dracula will prey on anyone, the main plot focuses on his corruption of female characters Lucy and Mina. By acting as the harbinger of female desire, he represents the potential loss of innocence/virginity by white, upper-class women in English society. The woman must be penetrated by the vampire's fangs to become a vampire themselves. Thereby, he becomes the embodiment of dangerous sexuality; those penetrated by him become monsters as well. 
Craft describes this as the woman being "kissed into a sudden sexuality" (119). In the case of Lucy, she literally becomes more sexualized in the physical descriptions given her. Her "voluptuous wantonness" is the result of Dracula's bite (Stoker 252). Though Stoker provides only this binary idea of women's sexuality, where women are either virgins or whores, they can't become whores without the penetration of a man, here presented as a force of evil. Lucy (the woman) isn't to blame for her position, that responsibility rests on Dracula (the man). However, in the end, both are killed for their condition.

This is the trope that I most wish to trouble in my thesis. Vanessa, like Lucy, doesn't wish to be bitten by a vampire. Unlike Lucy, when Vanessa is bitten against her will, she still maintains control over the self. Dracula is charismatic, attractive, and mostly in control of his thirst. Lucy and the Brides of Dracula (represented in the screenplay as groupies Kierra, Leanne, and Faith) are uncontrollable in their sexuality and bloodlust. I feel this to be an unfair dynamic and have therefore done away with it. This way, Vanessa can go toe-to-toe with Robbie as the woman he attempted to destroy. It creates a more powerful narrative in which the victim becomes the hero rather than a tragedy. Because of the genders of the characters, I encourage readers to look at this dynamic as one of female empowerment, or as empowerment of victims of gendered violence.

To young women, men can appear as the Other. For a teenage girl, men are not only unfathomable but often represent danger. As much as men are desired by heterosexual girls, they are presented with the potential risk of sexual assault and attack. This fear is highly present among women with Ferraro referring to it as the "master offense," or a fear that sits above all other crime-based fears (669). Though men also experience sexual assault, teenage girls are at particular risk, with both younger people and women being at higher risk for assault than their 
older or male counterparts (RAINN). Fears of sexual assault are, therefore, based in statistical likelihood. This fear translates well to the vampire genre, as both deal with fears regarding unwanted bodily penetration. The sexual threat of the vampire, as mentioned above, places him in a similar category to that of the rapist.

I do not wish to diminish sexual assault by comparing it to a fictional premise. My desire is to communicate the emotional and physical damage caused by non-consensual intercourse through a familiar story. I believe that putting a young audience through a rape scene is less constructive than allowing them to feel anger, fear, and sadness for a character in an allegorical incident and that audiences are intuitive enough to make connections without being told what to interpret. Moreover, the scene doesn't have to be interpreted as a one-to-one for sexual assault, as will be seen in the following section.

However, Robbie isn't the only Other. Once bitten, Vanessa also becomes a kind of Other because she can no longer live as a "normal" teenage girl because of her condition. The reference to Mary Shelley's Frankenstein (1818) in Lifeblood draws parallels between the creature and Vanessa, in that both have been made into something undesirable against their will, preventing them from living full lives. The creature and Vanessa turn on their creators, seeking revenge until the very end. Dracula and Frankenstein are both pioneering texts of the Gothic tradition, an important tradition to acknowledge in vampire works. In Gothic literature, vengeance is an important recurring theme. It is "both a fantasy of individual liberty and agency," as well as "a terrifying instantiation of the Other's agency" (Jones 140). In other words, Vanessa plays out the fantasy of revenge against her abuser but, because this is a horror film, does so in a way that provokes disturbance. 


\section{Fangirl Culture}

In the age of the Internet, fandom has become more present in the lives of young people. According to "Teenagers, Fandom, and Identity," teenagers use fandom as a form of personality construction (Lacasa, de la Fuente, Garcia-Pernía, Cortés). The personality of the fan is constructed through the public persona of their object of affection. Lacasa, de la Fuente, García-Pernía, and Cortés see this as a fairly positive thing, as teens use fan spaces to forge relationships with other fans and create lasting memories. What the article, and many others, have failed to consider is the fracturing of this personal relationship that happens when a fan is let down by their idol. Many young people place such high importance on keeping up with their idols that they do not pause to consider who the "real" idol is. In the wake of the \#MeToo movement, persona must be questioned and stars put under higher scrutiny, especially as they interact with young fans.

This is what I aim to do with the character of Robbie. He is an idol for Vanessa. She feels as if she knows him and has changed her persona to fit the aesthetics presented by him. However, when he reveals himself to be a predator, she must not only deal with the physical consequences of his attack but the mental consequences of persona disruption. Neither she nor Robbie were being their true selves, instead adopting more advantageous personas; in Robbie's case for fame and success, in Vanessa's case for belonging and desirability. If it has become commonplace for teens to base their personas around idols or cultural icons, what happens when these idol/fan relationships are broken must be considered.

Vampirism and the idol/fan relationship have an important connecting thread. Referring back to Dracula once more, the turning of Lucy was a reflection of Victorian social anxieties. The 
Victorians believed that the male contained active sexual desire, while the female was passive and had little to no sexual desire (Craft 108). If, as mentioned above, a woman can be "kissed into a sudden sexuality," (Craft 119) then the assumptions Victorians had about sexuality were wrong; a reality that was socially unacceptable. The same can be said about our modern treatment of fangirls in which the once-innocent fan is supposedly driven into mania by their idols. The word "hysteria" is commonly used to refer to fangirls, tracing as far back as a New York Times article on Beatlemania in 1965, as referenced in an article in The Week: "[The crowd's] immature lungs produced a sound so staggering, so massive, so shrill and sustained that it crossed the line from enthusiasm into hysteria and soon it was in the area of the classic Greek meaning of the world pandemonium — the region of the demons" (Friedman, Hansen). We must not forget that hysteria is a gendered word, hysteria coming from the Greek word hysteron, meaning uterus, or that "female hysteria" was historically used as a diagnosis to deny real women's issues (Laveda). The reference to demons forces this overall negative picture of fangirl behavior, behavior that could only be driven by madness. If we deem this a form of madness, unable to be understood by the average person, what makes us any better than the repressed Victorians?

Moreover, the vampire is not much different from the average boy band. The vampire and the boy band need the women they prey on to survive. For the vampire, this takes the form of blood necessitated by their physical thirst, for the boy band, it is money necessitated by a demanding music label. Instead of aiming vitriol at the fangirls who are allured by these marketing tactics and find joy in the work being produced, perhaps it would be more productive to be as critical of boy bands as we are of the vampire. To use the example of One Direction, ex-member Zayn 
Malik has been highly critical of his experience as a boy band member. "Whenever I would suggest something, it was like it didn't fit us," he told the Fader. "There was just a general conception that the management already had of what they want for the band and I just wasn't convinced with what we were selling" (Cooper). Malik suggests that their label led the members to pursue certain styles, personas, and concepts that didn't actually represent the members themselves. In this case, the men fangirls were falling in love with weren't actually real; they were simply ideas.

This isn't to say that members of boy bands are evil or monstrous, but their survival comes at a cost to others. The moral gray zone created by the boy band/fan dynamic is one worth questioning, especially if the result of their existence is an awakened teen sexuality that is criticized more often than the bands themselves. Though I don't believe boy bands to be evil, portraying them as such may open up conversations about fan exploitation and the ways in which fangirls are treated.

\section{The Monstrous-Feminine}

The most important genre theory that concerns Lifeblood is that of the monstrous-feminine, written on extensively by Creed. This concept aims to push back on the woman-as-victim trope, instead positing that the woman-as-monster illuminates us as to what men fear about women. According to Creed, "the presence of the monstrous-feminine in the popular horror film speaks to us more about male fears than about female desire or feminine subjectivity" (Creed 7). This view implicitly confirms that horror is typically conceived from the male perspective, by a male writer, and made real by a male director. It neglects to consider what possibilities lie in monstrous-feminine fiction written from the female perspective. 
When the perspective of the female monster is prized, monstrous-feminine fiction becomes potentially transgressive and empowering. Chusna and Mahmudah write about this in their article on Jennifer's Body and The Witch (dir. Eggers, 2013). Though only Jennifer's Body is written by a woman, both films use the monstrous-feminine trope to explore transgression of gender roles. Other films that employ the trope don't necessarily challenge gender roles in this way; for instance, The Brood (dir. Cronenberg, 1979) or Carrie have monstrous-feminine characters whose monstrosity is closely connected to the idea of the womb. Jennifer's Body and The Witch draw attention to the gender of their monsters, but problematize the connections to the female body. To use Jennifer as an example, she becomes a man-eating succubus after being kidnapped and tortured by a group of male musicians, a similarity to my own plot that has been noted to avoid parody or plagiarism. However, as Chusna and Mahmudah argue, Jennifer disrupts gender roles because "preying on boys as her victims suggests an instability of gender identity." (12) The Witch takes this further, with Chusna and Mahmudah proposing that the character of Thomasin is the one being castrated by her family's Puritan values (16). In this view, castration isn't necessarily defined as emasculation, but as a vital lack one feels in the soul.

My own work is firmly situated within this line of theory. Vanessa is a monstrous-feminine protagonist. Like Jennifer, her monstrosity is the result of an assault. Also like Jennifer, she is assaulted because of her position as a desirable subject, as both a sexual conquest and an active fan. However, Vanessa differs. Instead of villainizing Vanessa, as Jennifer is in her own film, Vanessa's anger and revenge is justified. This is achieved by allowing Vanessa to maintain her mental autonomy. She isn't so bloodthirsty as to have lost her moral compass. She maintains healthy relationships with her friends and family. The only thing that changes aside from her 
physical condition is her attitude toward Robbie and his band. She becomes more sympathetic due to her position as a "normal" high school girl who happens to have been turned into a vampire against her will.

I would also argue that Lifeblood contains similarities to The Witch. Both are coming-of-age stories that use fantasy concepts as allegory. Thomasin and Vanessa's newfound powers force them to acknowledge their own autonomy as young women. Though Thomasin ultimately joins the coven that kicked off her trauma, while Vanessa does not, they are each able to transcend the horrors of female puberty and become who they were meant to be. Finally, whereas Thomasin is emotionally castrated by her family's values, Vanessa is emotionally castrated when she first becomes a vampire.

Moreover, the relationship between castration and the monstrous-feminine trope plays a large role in the resolution of my story. In order to prevent Robbie from attacking more girls, Vanessa must castrate him. In this case, castration doesn't entail literal castration of the penis. Instead, Vanessa castrates the things Robbie needs to continue vampirizing and killing young women: His eyes and his teeth. Without these, he can no longer use mind control or bite necks. For Robbie, this would be a form of castration; his power is gone, taken away from him by the very person he once castrated himself. Her power reasserted, Vanessa becomes whole once more and able to resume her life, even under less-than-ideal conditions.

\section{Conclusion}

In this screenplay, these three major themes will be under consideration. My ultimate goal is to craft a work that uses horror as a way to think about contemporary talking points. As vampire stories have traditionally been used to articulate the fears of their societies, I wish to bring this 
into our current era. We live in a culture filled with unnecessary judgement and violence against all varieties of women and girls, with little in the way of proper cause. The world is no longer as vocally patriarchal as in the days of Stoker; rather, it is hidden in culture in insidious ways that all too often go unnoticed. By shining a light on this phenomenon through the eyes of a character who experiences this violence, I hope to educate young audiences as well as provide an empowering fantasy for those who have experienced violence.

\section{Bibliography}

Brood, The. Directed by David Cronenberg, performances by Oliver Reed and Samantha Eggar, New World Pictures, 1979.

Carrie. Directed by Brian De Palma, performances by Sissy Spacek and John Travolta, United Artists, 1976.

Chusna, Aidatul and Mahmudah, Shofi. "Female Monsters: Figuring Female Transgression in Jennifer's Body (2009) and The Witch (2013).” Humanoria, vol. 30, no. 1, 2018, pp. 10-16. Cooper, Duncan. “Zayn Malik's Next Direction.” The Fader, 15 Dec. 2015. Craft, Christopher. “'Kiss Me with Those Red Lips': Gender and Inversion in Bram Stoker's Dracula.” Representations, no. 8, 1984, pp. 107-133. JSTOR, www.jstor.org/stable/2928560. Ferraro, Kenneth F. "Women's Fear of Victimization: Shadow of Sexual Assault?” Social Forces, vol. 75, no. 2, 1996, pp. 667-690. JSTOR, www.jstor.org/stable/2580418.

Friedman, Jackie and Hansen, Lauren. "The mesmerizing hysteria of Beatlemania." The Week, date not published. 
Gennis, Sadie. "The Vampire Diaries Series Finale: Goodbye, Brother.” TV Guide, March 10, 2017.

Girl Walks Home Alone at Night, A. Directed by Ana Lily Amirpour, performances by Sheila Vand and Arash Marandi, Vice Films, 2014.

Jennifer's Body. Directed by Karyn Kusama, performances by Megan Fox and Amanda Seyfried, 20th Century Fox, 2009.

Jones, Anna Maria. “'What should make thee inaccessible to my fury?': Gothic Self-Posession, Revenge, and the Doctrine of Necessity in William Godwin's Caleb Williams." European Romantic Review, vol. 22, no. 2, pp. 137-154.

Lacasa, Pilar; de la Fuente, Julián; García-Pernía, María Ruth; Cortés, Sara. “Teenagers, Fandom and Identity.” Persona Studies, vol. 3, no. 2, 2017, pp. 51-65.

Laveda, Elena María Fernández; Martínez, Águeda Fernández; Antón, Irene Belda. "Hysteria: Female's Sexuality History." Cultura de los Cuidados, vol. 39, no. 8, 2014, pp. 63-70.

Love Witch, The. Directed by Anna Biller, performances by Samantha Robinson and Gian Keys, Oscilloscope Laboratories, 2016.

Łuksza, Agata. "Sleeping With A Vampire." Feminist Media Studies, vol. 15, no. 3, 2014, pp. 429-443.

Miller, Melissa. "Maybe Edward is the Most Dangerous Thing Out There: The Role of Patriarchy." Theorizing Twilight: Critical Essays on What's at Stake in a Post-Vampire World, 2011, pp. 165-177.

Otto, Katy. "Challenging Sexism in the Punk Community: A Different Kind of Dude Fest." Off Our Backs, vol. 34, no. 9/10, 2004, pp. 28-30. JSTOR, www.jstor.org/stable/20838168. 
RAINN. "Victims of Sexual Violence: Statistics." RAINN, www.rainn.org/statistics/victims-sexual-violence.

Rice, Anne. The Queen of the Damned. New York: Knopf, 1988. Print.

Shelley, Mary Wollstonecraft. Frankenstein. Oxford University Press, 2008. Print.

Stevenson, John Allen. "A Vampire in the Mirror: The Sexuality of Dracula." PMLA, vol. 103, no. 2, 1988, pp. 139-149. JSTOR, www.jstor.org/stable/462430.

Stoker, Bram. Dracula. New York: Random House, 1982. Print.

Witch, The. Directed by Robert Eggers, performances by Anya Taylor-Joy and Ralph Ineson, A24, 2015. 